\title{
The Effects of Closed Endotracheal Suction on Ventilation During Conventional and High-Frequency Oscillatory Ventilation
}

\author{
NICHOLAS J. KIRALY, DAVID G. TINGAY, JOHN F. MILLS, COLIN J. MORLEY, PETER A. DARGAVILLE, \\ AND BEVERLEY COPNELL
}

\begin{abstract}
Neonatal Research [N.J.K., D.G.T., J.F.M., C.J.M., P.A.D., B.C.], Murdoch Childrens Research Institute; Department of Neonatology [D.G.T., J.F.M., C.J.M., B.C.], The Royal Children's Hospital; Department of Paediatrics [D.G.T., C.J.M.], University of Melbourne, Parkville, Victoria, Australia 3052; Department of Paediatrics [P.A.D.], Royal Hobart Hospital and University of Tasmania, Hobart, Tasmania, Australia 7000
\end{abstract}

\begin{abstract}
In newborn infants, closed endotracheal tube (ETT) suction may reduce associated adverse effects, but it is not clear whether ventilation is maintained during the procedure. We aimed to determine the effect of ETT size, catheter size, and suction pressure on ventilation parameters measured distal to the ETT. Suction was performed on a test lung, ventilated with conventional (CMV) and high-frequency oscillatory ventilation (HFOV) using ETT sizes 2.5$4.0 \mathrm{~mm}$, catheter sizes 5-8 French gauge (Fr), and suction pressures 80-200 mm Hg. Tracheal and circuit peak inspiratory pressure, positive end-expiratory pressure, and tracheal tidal volume $\left(\mathrm{V}_{\mathrm{T}}\right)$ were recorded for each suction episode. During both CMV and HFOV, tracheal pressures and $\mathrm{V}_{\mathrm{T}}$ were considerably reduced by suctioning; this reduction was dependent on the combination of ETT, catheter, and suction pressure. Loss of $\mathrm{V}_{\mathrm{T}}$, inflation pressure (CMV), and pressure amplitude (HFOV) occurred primarily with insertion of the catheter, and loss of end-expiratory pressure (CMV) and mean tracheal pressure (HFOV) occurred with the application of suction. Circuit pressures were reduced to lesser degree. We conclude that airway pressures and $\mathrm{V}_{\mathrm{T}}$ are not maintained during closed endotracheal suction with either CMV or HFOV, and choice of equipment and settings will affect the degree of interruption to ventilation.
\end{abstract}

(Pediatr Res 66: 400-404, 2009)

$\mathrm{E}$ ndotracheal tube (ETT) suction is performed periodically on infants receiving mechanical ventilation to clear secretions from the ETT and airway. Although necessary, it is associated with adverse effects including atelectasis, hypoxemia, and cardiovascular instability, partly attributable to loss of airway pressure and interruption of ventilation (1-5). Closed suction, performed without disconnection from respiratory support, has been shown to reduce adverse effects (6-8), but whether ventilation is maintained during closed suction has not been demonstrated in a neonatal population.

With adult-sized ETTs, airway pressure has been shown to decrease during closed suction and concerns have been raised about the potential for very large negative airway pressures during the procedure $(4,9,10)$. However only one study has quantified pressure and tidal volume $\left(\mathrm{V}_{\mathrm{T}}\right)$ changes during

Received February 18, 2009; accepted May 26, 2009.

Correspondence: Nicholas J. Kiraly, B.Sc., Neonatal Research, Murdoch Childrens Research Institute, Department of Neonatology, The Royal Children's Hospital, Flemington Rd, Parkville Victoria 3052, Australia; e-mail: nicholas.kiraly@mcri.edu.au

Supported in part by a National Health and Medical Research Council Medical Research Fellowship (D.G.T.) and the National Health and Medical Research Council Medical program grant 384100 (B.C.). closed suction with neonatal equipment (11). Using an in vitro model, a considerable reduction in airway pressures and $\mathrm{V}_{\mathrm{T}}$ was demonstrated, particularly when a large catheter relative to the ETT was used. However, the authors did not report results using 5 or 7 French gauge (Fr) suction catheters, nor did they measure the effect of varying the suction pressure.

Airway pressures during closed suction are influenced by ventilation mode in adult models $(4,10)$, but this effect has not been studied using neonatal ventilators. Of particular interest is the performance of closed suction catheters during highfrequency oscillatory ventilation (HFOV), because closed suction is generally recommended for patients receiving this ventilation mode $(12,13)$.

This study aimed to determine the effect of ETT size, catheter size, and suction pressure on tracheal pressure and $\mathrm{V}_{\mathrm{T}}$ with closed suction of a neonatal lung model during conventional mechanical ventilation (CMV) and HFOV. Additionally, we aimed to measure ventilator circuit pressures during the procedure.

\section{MATERIALS AND METHODS}

Experimental model. The experimental arrangement is shown in Figure 1. An uncuffed ETT (Mallinckrodt, Rowville, Victoria, Australia) was connected to the trachea of an infant test lung (model 560li; MI Instruments, Grand Rapids, MI) with an ETT adaptor and sealed with silicon to prevent leak. A Ballard Trachcare in-line suction catheter (Kimberly-Clark, Roswell, GA) was placed between the ventilator circuit and ETT. Test lung compliance was set to $1 \mathrm{~mL} / \mathrm{cm} \mathrm{H}_{2} \mathrm{O}$ to represent an average compliance in our patient population, and no extra resistance was added to the airway.

Ventilation. The test lung was ventilated using both CMV and HFOV modes. CMV was delivered using a Dräger Babylog 8000 (Dräger, Lübeck, Germany) in time-cycled pressure-limited mode with the following settings: $20 \mathrm{~cm} \mathrm{H}_{2} \mathrm{O}$ positive inspiratory pressure (PIP); $5 \mathrm{~cm} \mathrm{H}_{2} \mathrm{O}$ positive endexpiratory pressure (PEEP); rate 60 per minute; inflation time $0.4 \mathrm{~s}$; circuit gas flow $8 \mathrm{~L} / \mathrm{min}$; and fraction of inspired oxygen 0.4 . HFOV was delivered using a Sensormedics 3100A oscillator (Sensormedics, Yorba Linda, CA) at mean airway pressure $\left(P_{\text {aw }}\right) 20 \mathrm{~cm} \mathrm{H}_{2} \mathrm{O}$, pressure amplitude $(\Delta P) 30 \mathrm{~cm} \mathrm{H}_{2} \mathrm{O}$, frequency $15 \mathrm{~Hz}$, I:E ratio 1:2, circuit gas flow $20 \mathrm{~L} / \mathrm{min}$, and fraction of inspired oxygen 0.4 . These settings were chosen to represent those commonly used in clinical practice.

Abbreviations: $\boldsymbol{\Delta} \boldsymbol{P}$, pressure amplitude during HFOV; $\mathbf{C M V}$, conventional mechanical ventilation; ETT, endotracheal tube; Fr, French gauge; HFOV, high-frequency oscillatory ventilation; $\boldsymbol{P}_{\boldsymbol{a w}}$, mean airway pressure during HFOV (measured in the ventilator circuit); MTP, mean tracheal pressure; PEEP, positive end-expiratory pressure; PIP, peak inspiratory pressure; $\mathbf{V}_{\mathbf{T}}$, tidal volume 


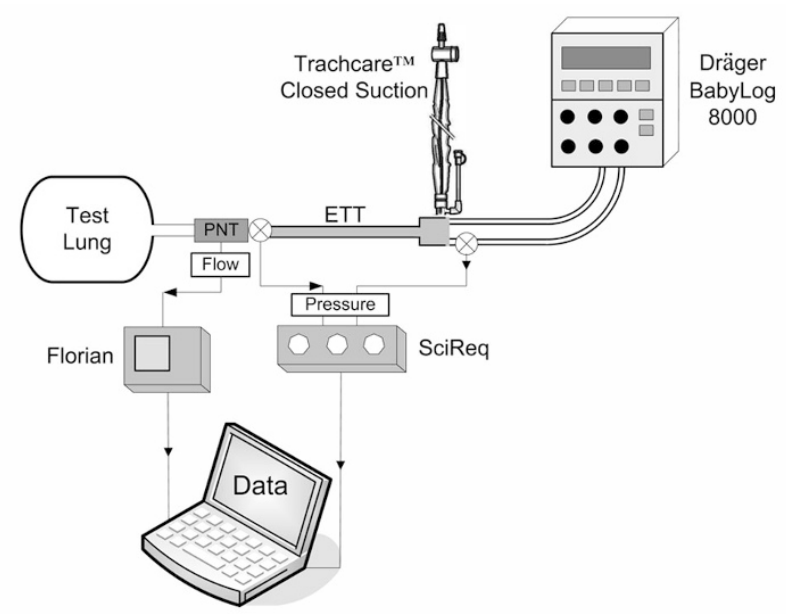

Figure 1. Diagram of the experimental design. ETT, endotracheal tube; PNT, pneumotachograph.

Suction procedure. Experiments were performed with all practicable combinations of neonatal ETT (sizes 2.5, 3.0, 3.5, and $4.0 \mathrm{~mm}$ internal diameter), suction catheter $(5,6,7$, and $8 \mathrm{Fr}$, which have external diameters of 1.7, 2.0, 2.3, and $2.7 \mathrm{~mm}$, respectively), and suction pressure (80, 120, 160, and $200 \mathrm{~mm} \mathrm{Hg}$ ), to cover the range used in clinical practice. A suction regulator (PM3000, Precision Medical Inc., Northampton, PA) was attached to wall suction, and pressure was set with the tubing occluded using a manometer (model RT-200; Timeter, St Louis, MO).

Before each suction episode was performed, a period of baseline ventilation ( $\geq 6 \mathrm{~s}$ in all cases) occurred to allow ventilation parameters to stabilize. For each suction episode, a catheter was passed to the tip of the ETT and held there for $6 \mathrm{~s}$ without suction. Suction was then applied for $6 \mathrm{~s}$, and then the catheter was withdrawn. The procedure was repeated six times with each combination of ETT, catheter size, and suction pressure during both ventilation modes.

Measurements. Ventilator circuit pressure was measured proximal to the ETT and tracheal pressure was measured $1 \mathrm{~cm}$ distal to the ETT. Both measurements were recorded using pressure transducers and signal amplifiers (Scireq, Montreal, PQ, Canada), which were calibrated against the Timeter manometer before the study. Tracheal gas flow was measured using a hot wire anemometer (Florian respiration monitor, Acutronic Medical Systems, Zug, Switzerland), calibrated to zero flow, placed distal to the ETT, and $1 \mathrm{~cm}$ distal to the tracheal pressure measurement port (Fig. 1). All pressure and flow signals were acquired at $200 \mathrm{~Hz}$ (CMV) or $1000 \mathrm{~Hz}$ (HFOV) using LabVIEW 6.0 (National Instruments, Austin, TX).

Data analysis. Proximal and distal PIP and PEEP and $\mathrm{V}_{\mathrm{T}}$ (calculated by integrating the flow wave signal) were determined for each inflation. From these measurements, inflation pressure (CMV) and $\Delta P$ (HFOV) were calcu- lated as the difference between PIP and PEEP. $P_{a w}$ (measured in the ventilator circuit) and mean tracheal pressure (MTP) during HFOV were calculated as the mean pressure during each ventilation cycle.

During each suction episode, three phases were identified from the tracheal pressure signal: baseline (normal ventilation), catheter insertion (before suction was applied), and during suction. For each parameter, mean values for the last $3 \mathrm{~s}$ (CMV, equal to 3 inflations) or $1 \mathrm{~s}$ (HFOV, equal to 15 inflations) of each phase were calculated and used in the analysis.

The effect of ETT size, catheter size, and suction on each of the measured parameters was determined using multiple linear regressions with the method of least squares, with $p$ values $<0.05$ considered statistically significant. Statistical analyses were performed using Stata (Version 9.0, Stata Corporation, College Station, TX). Values in text and figures are mean \pm SD.

\section{RESULTS}

CMV: Tracheal measurements. Changes from baseline in PEEP, inflation pressure, and $\mathrm{V}_{\mathrm{T}}$ during catheter insertion are shown in Table 1. Minimal changes in PEEP occurred, however, considerable reduction in inflation pressure and $\mathrm{V}_{\mathrm{T}}$ were observed, with greater reduction in these parameters associated with increasing catheter size ( $p<0.05$ in all cases).

During suction, tracheal PEEP fell by up to $110 \mathrm{~cm} \mathrm{H}_{2} \mathrm{O}$, depending on the combination of ETT, catheter and suction pressure (Fig. 2). $\mathrm{V}_{\mathrm{T}}$ (Fig. 3) was also reduced, and this reduction was greatest where a large catheter relative to the ETT was used. Inflation pressure followed a similar pattern to $\mathrm{V}_{\mathrm{T}}$, with reduction being greatest with large catheters and being relatively unaffected by suction pressure. With a 4.0 ETT, an $8 \mathrm{Fr}$ catheter, and either 160 or $200 \mathrm{~mm} \mathrm{Hg}$ suction pressure, the ventilator stopped delivering inflations; thus inflation pressure and $\mathrm{V}_{\mathrm{T}}$ were reduced to zero.

Multiple linear regression analyses demonstrated that ETT and catheter size had significant independent effects in determining PEEP, inflation pressure and $\mathrm{V}_{\mathrm{T}}$ during suction $(p<0.001$ in all cases). Suction pressure had no independent effect on $\operatorname{PEEP}(p=$ $0.858)$, but was independently significant in determining inflation pressure and $\mathrm{V}_{\mathrm{T}}(p<0.001$ in each case). Interaction between variables was observed with each combination of independent variables ( $p<0.001$ in each case), except between ETT and catheter size during regression of $\mathrm{V}_{\mathrm{T}}(p=0.424)$. The multiple linear regression models used accurately described PEEP $\left(R^{2}=\right.$ $0.83)$, inflation pressure $\left(R^{2}=0.79\right)$ and $\mathrm{V}_{\mathrm{T}}\left(R^{2}=0.91\right)$.

Table 1. Suction catheter insertion - change in ventilation parameters from baseline during insertion of a closed suction catheter (no suction applied)

\begin{tabular}{|c|c|c|c|c|c|c|c|}
\hline \multirow[b]{2}{*}{ ETT, mm ID } & \multirow[b]{2}{*}{ Catheter, Fr } & \multicolumn{3}{|c|}{$\mathrm{CMV}$} & \multicolumn{3}{|c|}{ HFOV } \\
\hline & & $\triangle$ PEEP, $\mathrm{cm} \mathrm{H}_{2} \mathrm{O}$ & IP, $\%$ & $\mathrm{~V}_{\mathrm{T}}, \%$ & $\Delta \mathrm{MTP}, \mathrm{cm} \mathrm{H}_{2} \mathrm{O}$ & Trach $\Delta P, \%$ & $\mathrm{~V}_{\mathrm{T}}, \%$ \\
\hline \multirow[t]{2}{*}{2.5} & 5 & $0.7 \pm 0.1$ & $62 \pm 2$ & $59 \pm 4$ & $0.2 \pm 0.0$ & $50 \pm 1$ & $35 \pm 1$ \\
\hline & 6 & $2.8 \pm 0.1$ & $24 \pm 2$ & $21 \pm 2$ & $0.4 \pm 0.0$ & $22 \pm 1$ & $10 \pm 1$ \\
\hline \multirow[t]{3}{*}{3.0} & 5 & $0.0 \pm 0.0$ & $92 \pm 1$ & $90 \pm 1$ & $0.1 \pm 0.0$ & $70 \pm 1$ & $55 \pm 1$ \\
\hline & 6 & $0.3 \pm 0.1$ & $73 \pm 1$ & $70 \pm 2$ & $0.0 \pm 0.0$ & $53 \pm 1$ & $35 \pm 1$ \\
\hline & 7 & $1.8 \pm 0.1$ & $39 \pm 2$ & $36 \pm 2$ & $0.2 \pm 0.0$ & $31 \pm 1$ & $15 \pm 1$ \\
\hline \multirow[t]{4}{*}{3.5} & 5 & $0.0 \pm 0.0$ & $98 \pm 1$ & $98 \pm 1$ & $0.1 \pm 0.0$ & $80 \pm 0$ & $69 \pm 1$ \\
\hline & 6 & $0.0 \pm 0.0$ & $94 \pm 1$ & $93 \pm 1$ & $0.1 \pm 0.1$ & $70 \pm 1$ & $54 \pm 1$ \\
\hline & 7 & $0.2 \pm 0.1$ & $79 \pm 3$ & $76 \pm 3$ & $0.1 \pm 0.1$ & $56 \pm 1$ & $38 \pm 1$ \\
\hline & 8 & $1.7 \pm 0.2$ & $42 \pm 2$ & $40 \pm 2$ & $0.1 \pm 0.0$ & $30 \pm 1$ & $14 \pm 1$ \\
\hline \multirow[t]{4}{*}{4.0} & 5 & $0.0 \pm 0.0$ & $99 \pm 1$ & $99 \pm 1$ & $0.1 \pm 0.1$ & $88 \pm 1$ & $84 \pm 1$ \\
\hline & 6 & $0.0 \pm 0.0$ & $98 \pm 1$ & $98 \pm 1$ & $0.1 \pm 0.0$ & $82 \pm 0$ & $75 \pm 1$ \\
\hline & 7 & $0.0 \pm 0.0$ & $98 \pm 1$ & $98 \pm 1$ & $0.2 \pm 0.0$ & $76 \pm 1$ & $65 \pm 1$ \\
\hline & 8 & $0.1 \pm 0.2$ & $96 \pm 2$ & $95 \pm 3$ & $0.2 \pm 0.0$ & $22 \pm 0$ & $55 \pm 0$ \\
\hline
\end{tabular}

Data mean \pm SD.

ID, inner diameter; IP, inflation pressure; $\%$, percent of baseline value measured; trach $\Delta P$, pressure amplitude measured in the trachea. 

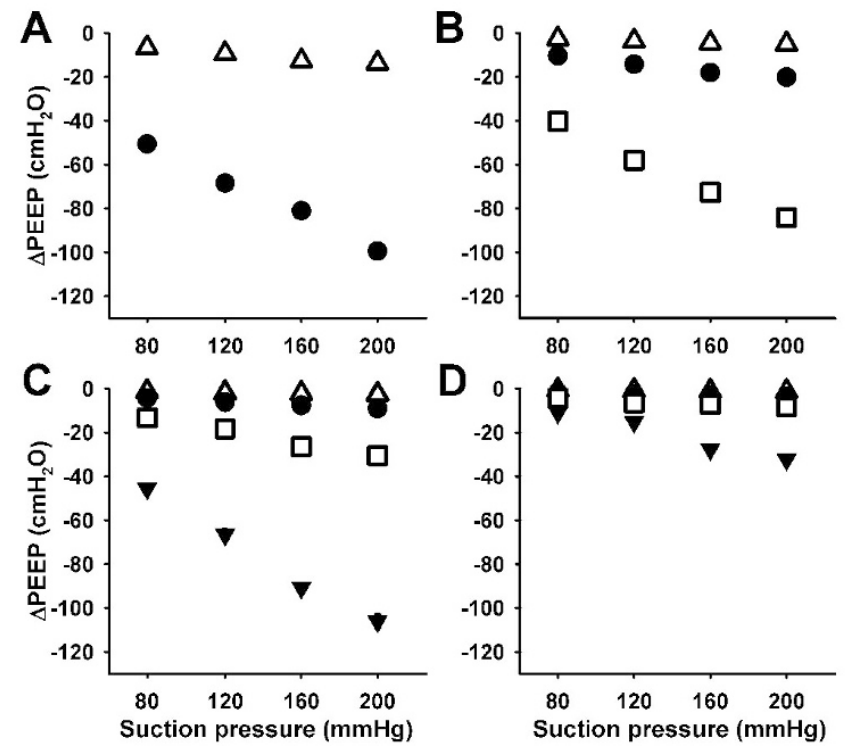

Figure 2. $A-D$, change in tracheal PEEP $\left(\mathrm{cm} \mathrm{H}_{2} \mathrm{O}\right)$ from baseline during CMV for suction of ETT internal diameters $2.5 \mathrm{~mm}(A), 3.0 \mathrm{~mm}(B), 3.5 \mathrm{~mm}(C)$, and $4.0 \mathrm{~mm}(D)$ with catheter sizes $5 \operatorname{Fr}(\Delta), 6$ Fr $(\bullet), 7$ Fr $(\square)$, and 8 Fr $(\nabla)$.
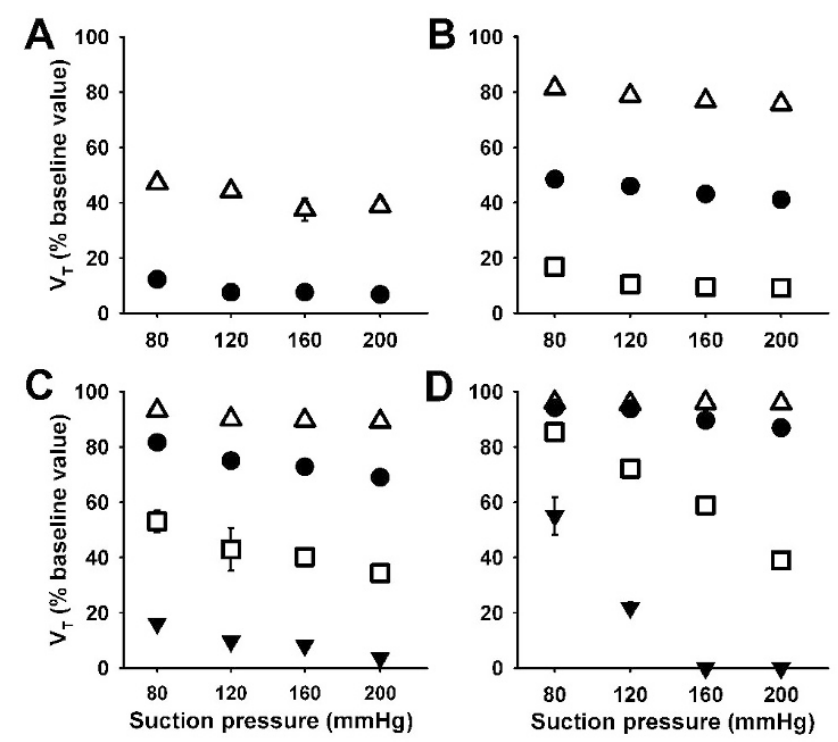

Figure 3. $A-D$, delivered $\mathrm{V}_{\mathrm{T}}$ (expressed as percent of baseline) during CMV for suction of ETT internal diameters $2.5 \mathrm{~mm}(A), 3.0 \mathrm{~mm}(B), 3.5 \mathrm{~mm}(C)$, and 4.0 $\mathrm{mm}(D)$ with catheter sizes $5 \operatorname{Fr}(\Delta), 6 \operatorname{Fr}(\bullet), 7 \operatorname{Fr}(\square)$, and 8 Fr $(\boldsymbol{\nabla})$.

CMV: Ventilator circuit measurements. Circuit PEEP was maintained during CMV with all combinations tested, with the exception of $4.0 \mathrm{~mm}$ ETT, 8 Fr catheter, and either 160 or 200 $\mathrm{mm} \mathrm{Hg}$ suction pressure, where the ventilator ceased delivering inflations. In this circumstance, ventilator circuit pressure stabilized at $-4.2 \mathrm{~cm} \mathrm{H}_{2} \mathrm{O}$. Circuit PIP was reduced by $\geq 3 \mathrm{~cm}$ $\mathrm{H}_{2} \mathrm{O}$ only with the following combinations of ETT/catheter/ suction pressure: $3.5 \mathrm{~mm} / 8 \mathrm{Fr} / 200 \mathrm{~mm} \mathrm{Hg}$; $4.0 \mathrm{~mm} / 7 \mathrm{Fr} / 160$ or $200 \mathrm{~mm} \mathrm{Hg} ; 4.0 \mathrm{~mm} / 8 \mathrm{Fr} / 120$ or 160 or $200 \mathrm{~mm} \mathrm{Hg}$. With these combinations, circuit PIP was reduced by up to $10.9 \mathrm{~cm}$ $\mathrm{H}_{2} \mathrm{O}$. In addition, PIP was equal to PEEP when the ventilator stopped delivering inflations as described earlier.

HFOV: Tracheal measurements. Minimal changes in MTP were recorded during catheter insertion. There was marked

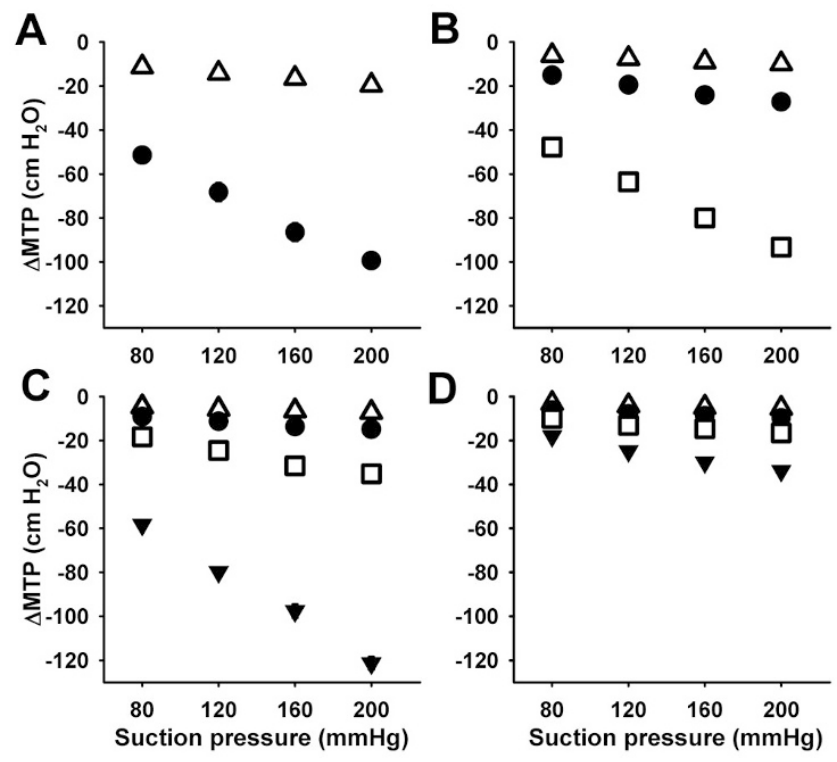

Figure 4. $A-D$, change in MTP $\left(\mathrm{cm} \mathrm{H}_{2} \mathrm{O}\right)$ from baseline during CMV for suction of ETT internal diameters $2.5 \mathrm{~mm}(A), 3.0 \mathrm{~mm}(B), 3.5 \mathrm{~mm}(C)$, and $4.0 \mathrm{~mm}(D)$ with catheter sizes $5 \operatorname{Fr}(\Delta), 6 \operatorname{Fr}(\bullet), 7 \operatorname{Fr}(\square)$, and 8 Fr $(\nabla)$.

reduction in both $\Delta P$ and $\mathrm{V}_{\mathrm{T}}$ during catheter insertion and considerable variation between combinations of ETT and catheter, with an increase in catheter size resulting in reduction in these parameters in all circumstances $(p<0.001$; Table 1).

Reduction in MTP during suction was between 3 and 121 $\mathrm{cm} \mathrm{H}_{2} \mathrm{O}$ from the baseline value of approximately $20 \mathrm{~cm} \mathrm{H}_{2} \mathrm{O}$ (Fig. 4). Delivered $\mathrm{V}_{\mathrm{T}}$ was reduced to $16-83 \%$ of baseline depending on the combination of ETT and catheter (Fig. 5). Tracheal $\Delta P$ was reduced to $15-20 \%$ of baseline where the largest catheter for ETT sizes 2.5, 3.0, and 3.5 were used. Suction pressure had little influence on tracheal $\Delta P$.

ETT and catheter size both had significant independent effects on determining MTP, tracheal $\Delta P$, and $\mathrm{V}_{\mathrm{T}}$ during suction $(p<0.001)$, as determined by multiple regression analyses. Suction pressure had no independent effect on any of the outcome variables ( $p>0.6$ in all cases). Interaction between each of the three predictor variables was significant in determining MTP $(p<0.001$ in each case). Interaction was observed between ETT and catheter size for both $\Delta P$ and $\mathrm{V}_{\mathrm{T}}$ $(p<0.001$ in each case), whereas no interaction was seen between suction pressure and either of the other variables $(p>$ 0.3 in each case). The independent variables included in the model accurately predicted MTP $\left(R^{2}=0.83\right), \Delta P\left(R^{2}=0.97\right)$ and $\mathrm{V}_{\mathrm{T}}\left(R^{2}=0.99\right)$ during suction with HFOV.

HFOV: Ventilator Circuit measurements. During HFOV, circuit $P_{a w}$ was reduced in all circumstances during closed suction (Table 2). Larger reductions in $P_{a w}$ were observed with increasing catheter size, ETT size, and suction pressure. Circuit $\Delta P$ was minimally affected by the procedure, being raised by up to $1.9 \mathrm{~cm} \mathrm{H}_{2} \mathrm{O}$ when the largest catheter for each ETT size was used.

\section{DISCUSSION}

This bench test, by investigating a practical and clinically relevant range of suction apparatus for newborn infants, is the 

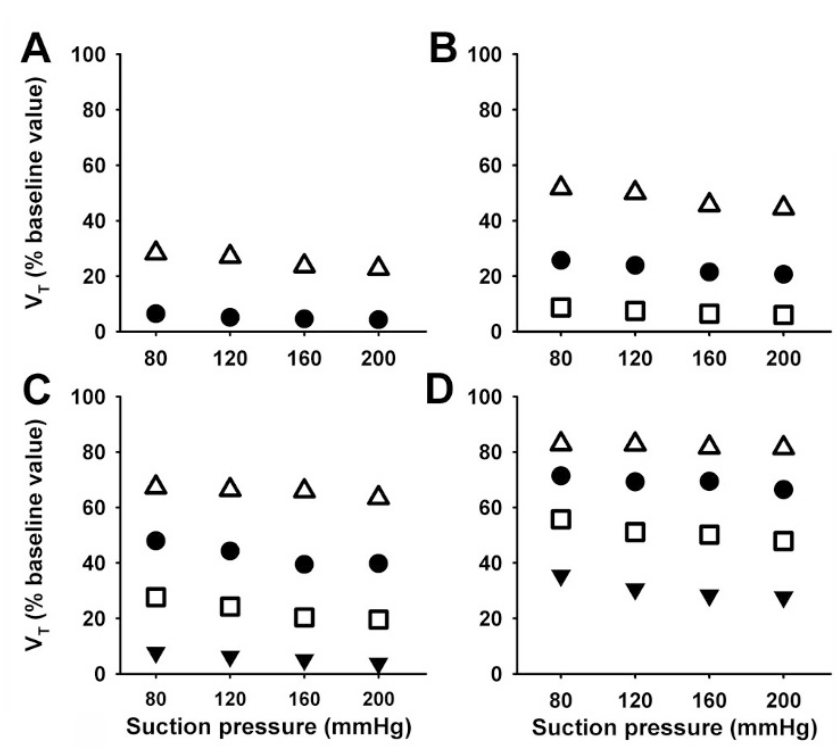

Figure 5. $A-D$, delivered $\mathrm{V}_{\mathrm{T}}$ (expressed as percent of baseline) during HFOV for suction of ETT internal diameters $2.5 \mathrm{~mm}(A), 3.0 \mathrm{~mm}(B), 3.5 \mathrm{~mm}$ $(C)$, and $4.0 \mathrm{~mm}(D)$ with catheter sizes $5 \mathrm{Fr}(\Delta), 6 \mathrm{Fr}(\bullet), 7 \mathrm{Fr}(\square)$, and 8 Fr $(\mathbf{\nabla})$.

Table 2. High frequency oscillatory ventilation-reduction in circuit $\mathrm{P}_{\text {aw }}$ from baseline during the application of suction $\left(\mathrm{cm} \mathrm{H}_{2} \mathrm{O}\right)$

\begin{tabular}{cccccc}
\hline & & \multicolumn{4}{c}{ Suction pressure $(\mathrm{mm} \mathrm{Hg})$} \\
\cline { 3 - 6 } ETT, mm ID & Catheter, Fr & 80 & 120 & 160 & 200 \\
\hline 2.5 & 5 & 2.0 & 2.6 & 3.0 & 3.3 \\
& 6 & 2.8 & 3.6 & 4.1 & 4.6 \\
3.0 & 5 & 2.1 & 2.6 & 3.0 & 3.4 \\
& 6 & 3.5 & 4.3 & 5.0 & 5.6 \\
3.5 & 7 & 4.2 & 5.3 & 6.3 & 6.9 \\
& 5 & 2.1 & 2.6 & 3.0 & 3.3 \\
& 6 & 3.6 & 4.4 & 5.1 & 5.6 \\
& 7 & 5.1 & 6.3 & 7.2 & 7.9 \\
4.0 & 8 & 5.5 & 6.9 & 8.0 & 8.8 \\
& 5 & 1.9 & 2.6 & 3.0 & 3.3 \\
& 6 & 3.4 & 4.4 & 5.1 & 5.6 \\
& 7 & 4.9 & 6.4 & 7.3 & 8.1 \\
& 8 & 6.7 & 8.6 & 9.8 & 10.7 \\
\hline
\end{tabular}

ID, inner diameter.

first to report the effect of closed system suction on ventilation pressure and $\mathrm{V}_{\mathrm{T}}$ delivered to a test lung during CMV and HFOV. We found that tracheal pressures and $\mathrm{V}_{\mathrm{T}}$ were affected by the combination of the ETT and catheter dimensions, and also the suction pressure applied to the catheter, with larger catheters and higher suction pressures associated with lower tracheal pressures and delivered $\mathrm{V}_{\mathrm{T}}$.

Comparison between the 'catheter insertion' and 'suction' phases shows that during both CMV and HFOV, ventilation is interrupted by simply inserting the catheter, and that distending pressure (tracheal PEEP or MTP) is lost only after suction is applied. This finding is significant because it has previously been proposed that the time taken to perform the entire suction procedure is less important with closed suction than open, because ventilation is assumed to be maintained (14). We also found that when the largest catheter for a given ETT is used, delivered $\mathrm{V}_{\mathrm{T}}$ is reduced to $<10 \%$ with both $\mathrm{CMV}$ and $\mathrm{HFOV}$, and distending pressure becomes extremely negative when suction is applied. However, circuit pressures are only minimally affected, therefore, clinicians may be unaware of the magnitude of negative pressure occurring within the airways. Even with catheter sizes currently recommended for neonatal airways $(15,16)$, pressure was dramatically reduced: tracheal PEEP during CMV was reduced by up to $60 \mathrm{~cm} \mathrm{H}_{2} \mathrm{O}$, and during HFOV, MTP was reduced by $17-70 \mathrm{~cm} \mathrm{H}_{2} \mathrm{O}$. In clinical practice, even a small drop in pressure may be significant (17), and a large reduction in pressure may result in mucosal damage, airway collapse, and significant atelectasis $(6,18,19)$.

Morrow and Argent (20) recently recommended smaller catheter sizes than previous recommendations for pediatric and neonatal patients, with the choice of catheter depending on the consistency of secretions. According to our results, catheter selection using these recommendations based on thin secretions would avoid subatmospheric airway pressures if used with $\leq 200 \mathrm{~mm} \mathrm{Hg}$ suction pressure. However, a 6-Fr catheter recommended for a 2.5 ETT in the presence of thick secretions could result in large subatmospheric airway pressures if suction continued once secretions were cleared, and $\mathrm{V}_{\mathrm{T}}$ is likely to be significantly reduced during the procedure. Furthermore, such secretions may adhere to the ETT inner surface and increase resistance $(21,22)$, which may lead to airway pressures lower than have been recorded in this study.

The only other study to measure "intratracheal" pressure during closed suction with neonatal apparatus was performed using a similar test lung and compliance setting to this study, but used only a single suction pressure of $100 \mathrm{~mm} \mathrm{Hg} \mathrm{(11).}$ Despite different ventilator settings, PEEP was within $3 \mathrm{~cm}$ $\mathrm{H}_{2} \mathrm{O}$ and delivered $\mathrm{V}_{\mathrm{T}}$ was within $20 \%$ of our findings for all comparable combinations of ETT and catheter, when our data are interpolated to $100 \mathrm{~mm} \mathrm{Hg}$ suction pressure.

Airway pressures during closed suction in this study were considerably lower than we have previously described during open suction, particularly when using larger sized catheters in relation to the ETT (23). Airway pressures during open suction are a function of catheter size, and the difference in cross-sectional area between the ETT and the catheter (2325). Flow between the ETT and catheter is predominantly laminar during open suction (23), but during closed suction, the dynamic circuit pressure and gas flow may lead to turbulent flow within this space increasing resistance and resulting in reduced tracheal pressures. This effect may be particularly important with infant ETTs, as this space is relatively small. Studies comparing airway pressures during open and closed suction using adult-sized equipment have reported higher pressures with closed suction than with open, at least under similar conditions to our study $(4,10)$. These findings suggest that the larger area between the adult ETT and catheter may allow for flow to be predominantly laminar despite the dynamic flow conditions of closed suction, and therefore pressure loss to be less than with ETTs used for infants.

Our study has several limitations. In the clinical setting, airway pressure and $\mathrm{V}_{\mathrm{T}}$ are likely to be influenced by the volume and consistency of mucus. Secretions adhering to the ETT can cause considerable narrowing of the ETT lumen 
$(21,22)$, which could result in greater loss of pressure and $\mathrm{V}_{\mathrm{T}}$ during suction, whereas secretions entering the catheter will tend to inhibit a fall in pressure (26). However, suction in the absence of secretions can occur in clinical practice (26) and may occur toward the end of the procedure when secretions have been cleared, especially with multiple passes of the catheter. This experiment was conducted at a single compliance setting and excluded any effect from patient effort. In clinical practice, spontaneous breathing might affect ventilation during suction, while the collapsible lungs of infants with respiratory distress might cause greater reduction in delivered $\mathrm{V}_{\mathrm{T}}$ than was observed with the constant compliance lung used in this experiment. Leak around the ETT was similarly excluded, as its variable magnitude would make testing complicated. Although leak occurs primarily during the higherpressure conditions of inflation (27) and might therefore be less likely to occur during suction, the effect of leak on airway pressure during the procedure is yet to be determined. Finally, investigating the effects of suction using other ventilator settings and modes commonly used in neonatal practice, such as $\mathrm{V}_{\mathrm{T}}$-targeted ventilation, would increase understanding of the interaction between closed suction and ventilation.

In conclusion, this study demonstrates that, in vitro, airway pressures and $\mathrm{V}_{\mathrm{T}}$ are not maintained during closed suction with either CMV or HFOV. Major determinants of loss in tracheal PEEP and MTP are the combination of ETT size, suction catheter size, and suction pressure. The major determinants of tracheal $\Delta P$, inflation pressure, and $\mathrm{V}_{\mathrm{T}}$ are ETT and catheter size. During ETT suction, the magnitude of subatmospheric tracheal pressure generated is potentially large and may cause atelectasis or airway collapse. Therefore, choice of catheter size and suction pressure has important clinical implications.

Acknowledgments. The author thank Associate Professor Susan Donath for valuable help with the statistical analysis, Dräger Medical for the use of a Dräger Babylog 8000 ventilator, and the Clinical Technology Service, Royal Children's Hospital for use of equipment and resources.

\section{REFERENCES}

1. Hoellering AB, Copnell B, Dargaville PA, Mills JF, Morley CJ, Tingay DG 2008 Lung volume and cardiorespiratory changes during open and closed endotracheal suction in ventilated newborn infants. Arch Dis Child Fetal Neonatal Ed 93:F436F441
2. Kerem E, Yatsiv I, Goitein KJ 1990 Effect of endotracheal suctioning on arterial blood gases in children. Intensive Care Med 16:95-99

3. Kuzenski BM 1978 Effect of negative pressure on tracheobronchial trauma. Nurs Res 27:260-263

4. Lindgren S, Almgren B, Hogman M, Lethvall S, Houltz E, Lundin S, Stenqvist O 2004 Effectiveness and side effects of closed and open suctioning: an experimental evaluation. Intensive Care Med 30:1630-1637

5. Simbruner G, Coradello H, Fodor M, Havelec L, Lubec G, Pollak A 1981 Effect of tracheal suction on oxygenation, circulation, and lung mechanics in newborn infants. Arch Dis Child 56:326-330

6. Choong K, Chatrkaw P, Frndova H, Cox PN 2003 Comparison of loss in lung volume with open versus in-line catheter endotracheal suctioning. Pediatr Crit Care Med 4:69-73

7. Kalyn A, Blatz S, Feuerstake S, Paes B, Bautista C 2003 Closed suctioning of intubated neonates maintains better physiologic stability: a randomized trial. J Perinatol 23:218-222

8. Woodgate PG, Flenady V 2001 Tracheal suctioning without disconnection in intubated ventilated neonates. Cochrane Database Syst Rev 2:CD003065

9. Frengley RW, Closey DN, Sleigh JW, Torrance JM 2001 The effect of closed system suction on airway pressures when using the Servo 300 ventilator. Crit Care Resusc $3: 230-235$

10. Stenqvist O, Lindgren S, Karason S, Sondergaard S, Lundin S 2001 Warning! Suctioning. A lung model evaluation of closed suctioning systems. Acta Anaesthesiol Scand 45:167-172

11. Monaco FJ, Meredith KS 1992 A bench test evaluation of a neonatal closed tracheal suction system. Pediatr Pulmonol 13:121-123

12. Higgins J, Estetter B, Holland D, Smith B, Derdak S 2005 High-frequency oscillatory ventilation in adults: respiratory therapy issues. Crit Care Med 33:S196-S203

13. Sweeney A-M, Lyle J, Ferguson ND 2005 Nursing and infection-control issues during high-frequency oscillatory ventilation. Crit Care Med 33:S204-S208

14. Van Hooser DT 2002 Airway Clearance with Closed-System Suctioning. American Association of Critical-Care Nurses, Aliso Viejo, CA, p 10

15. Goldsmith JP, Karotkin EH 2003 Assisted Ventilation of the Neonate. WB Saunders Company, Philadelphia, PA, pp 116-117

16. Shann F 2008 Drug Doses. Collective Pty Ltd, Melbourne, Australia, p i

17. van Kaam AH, de Jaegere A, Haitsma JJ, Van Aalderen WM, Kok JH, Lachmann B 2003 Positive pressure ventilation with the open lung concept optimizes gas exchange and reduces ventilator-induced lung injury in newborn piglets. Pediatr Res 53:245-253

18. Brodsky L, Reidy M, Stanievich JF 1987 The effects of suctioning techniques on the distal tracheal mucosa in intubated low birth weight infants. Int J Pediatr Otorhinolaryngol 14:1-14

19. Turner BS, Loan LA 2000 Tracheobronchial trauma associated with airway management in neonates. AACN Clin Issues 11:283-299

20. Morrow BM, Argent AC 2008 A comprehensive review of pediatric endotracheal suctioning: Effects, indications, and clinical practice. Pediatr Crit Care Med 9:465477

21. Boque MC, Gualis B, Sandiumenge A, Rello J 2004 Endotracheal tube intraluminal diameter narrowing after mechanical ventilation: use of acoustic reflectometry. Intensive Care Med 30:2204-2209

22. Karason S, Sondergaard S, Lundin S, Wiklund J, Stenqvist O 2001 Direct tracheal airway pressure measurements are essential for safe and accurate dynamic monitoring of respiratory mechanics. A laboratory study. Acta Anaesthesiol Scand 45:173179

23. Kiraly NJ, Tingay DG, Mills JF, Morley CJ, Copnell B 2008 Negative tracheal pressure during neonatal endotracheal suction. Pediatr Res 64:29-33

24. Morrow BM, Futter MJ, Argent AC 2004 Endotracheal suctioning: from principles to practice. Intensive Care Med 30:1167-1174

25. Rosen M, Hillard EK 1960 The use of suction in clinical medicine. Br J Anaesth 32:486-504

26. Morrow B, Futter M, Argent A 2006 Effect of endotracheal suction on lung dynamics in mechanically-ventilated paediatric patients. Aust J Physiother 52:121126

27. Kondo T, Matsumoto I, Lanteri CJ, Sly PD 1997 Respiratory mechanics during mechanical ventilation: a model study on the effects of leak around a tracheal tube. Pediatr Pulmonol 24:423-428 